\title{
Relaxation of tracheomotor tone by PEEP: influence of hypocapnia and acidemia
}

The effect of PEEP on airway smooth muscle tone is difficult to assess using standard lung resistance and compliance techniques. In this study we isolated the extrathoracic trachea from lower airway pressure by performing a low cervical tracheostomy in dogs. We then measured the pressure $\left(P_{T E}\right)$ within a water-filled cuff of an endotracheal tube which was placed in the isolated extra-thoracic tracheal segment above the tracheostomy as a measure of tracheomotor tone.

Sudden application of $10 \mathrm{~cm} \mathrm{H}_{2} \mathrm{O}$ PEEP in normocapneic animals $\left(\mathrm{PaCO}_{2}=5.6 \pm 0.2 \mathrm{kPa}\right)$ caused an immediate dilation in this extrathoracic tracheal segment $\left(P_{T E}\right.$ decreased from $5.7 \pm 0.3 \mathrm{kPa}$ to $2.4 \pm 0.4 \mathrm{kPa}$ ). This decrease in tracheomotor tone was transient, returning to control level by four minutes in spite of $10 \mathrm{~cm} \mathrm{H}_{2} \mathrm{O}$ PEEP mainained on the lower ainway.

With zero end-expiratory pressure the respiratory rate was increased from 9 to 19 breath per minute and $\mathrm{PaCO}_{2}$ reduced to $3.9 \pm 0.2 \mathrm{kPa}$. No detectable tracheomotor dilation was observed after the application of $10 \mathrm{Cm} \mathrm{H}_{2} \mathrm{O}$ PEEP to the lower airway. When exogenous $\mathrm{CO}_{2}$ was added to the inspired gas mixture at a respiratory rate of $19 / \mathrm{min}$, the $\mathrm{PaCO}_{2}$ increased from $4.2 \pm 0.2 \mathrm{kPa}$ to 6.7

\section{Key words}

RESPIRATORY SYSTEM: airway tone, PEEP.

From the Department of Anaesthesia, St. Michael's Hospital, University of Toronto. Supported by the Ontario Heart Foundation.

Address correspondence to: Dr. Robert J. Byrick, Dept. of Anaesthesia, St. Michael's Hospital, 30 Bond Street, Toronto, Ontario, MSB IW8. $\pm 0.4 \mathrm{kPa}$ and a tracheomotor dilation in response to PEEP was again detectable.

Finally, a $0.1 \mathrm{~N}$ infusion of $\mathrm{HCl}$ was infused into hypocapneic animals $\left(\mathrm{PaCO}_{2}=3.7 \pm 0.3 \mathrm{kPa} ; \mathrm{pH}=\right.$ $7.47 \pm 0.02$ ). After $30-70$ minutes, $\mathrm{pH}$ decreased to 7.26 \pm 0.02 and $\mathrm{PaCO}_{2}$ remained $3.5 \pm 0.3 \mathrm{kPa} . \mathrm{A}$ detectable, but reduced tracheomotor response to $10 \mathrm{~cm}$ $\mathrm{H}_{2} \mathrm{O}$ PEEP was then observed. We conclude that:

1. sudden application of $10 \mathrm{~cm} \mathrm{H}_{2} \mathrm{O}$ PEEP causes transient relaxation of tracheomotor tone $(<4$ minutes $)$.

2. this tracheomotor relaxation is diminished by hyperventilation with hypocapnia.

3. the reduced responsiveness to PEEP of tracheal smooth muscle during hyperventilation is partially returned by either adding $\mathrm{CO}_{2}$ to the inspired gas mixture or systemic acidification with $0.1 \mathrm{~N} \mathrm{HCl}$.

This study suggests that the tracheal dilation resulting from increased lung volume afier $P E E P$ is transient and is variable depending on such factors as systemic acid-base status, alveolar and arterial $\mathrm{PaCO}_{2}$, lung volume as well as the existing balance of autonomic influences on airway tone.

A reflex decrease in canine tracheal smooth muscle tone secondary to an acute sustained lung inflation has been demonstrated by Nadel. ' Recently Qvist et $a l^{2}$ suggested that high levels of positive endexpiratory pressure (PEEP) may be useful in combating the air-trapping which accompanies bronchospasm in refractory asthmatic states. We have designed this study to investigate the effect of a sudden, sustained application of $10 \mathrm{~cm} \mathrm{H}_{2} \mathrm{O}$ PEEP on tracheal smooth muscle tone in a mongrel dog model, as well as the influence of hypocapnia and acidemia on this response. 


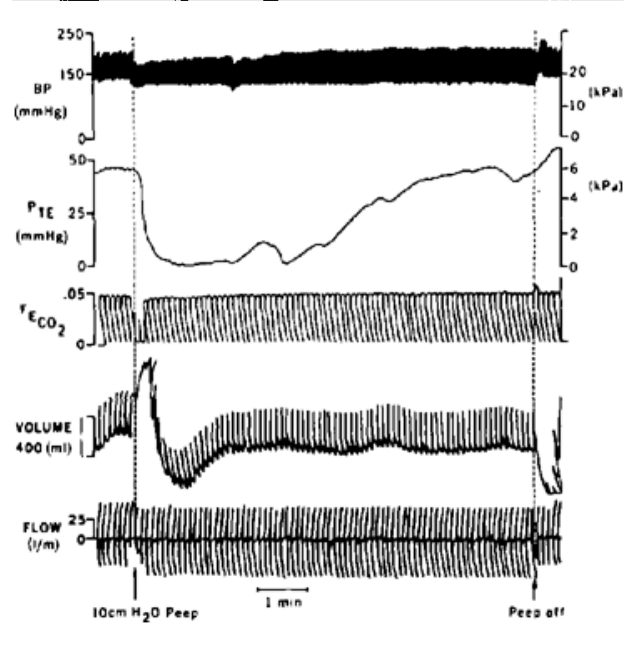

FIGURE 1 A typical decrease of extrathoracic cuff pressure (PTE) to the sudden application of PEEP $\left(10 \mathrm{~cm} \mathrm{H} \mathrm{H}_{2} \mathrm{O}\right)$ at normocapnia $\left(\mathrm{PaCO}_{2}=38 \mathrm{~mm} \mathrm{Hg}(5.1 \mathrm{kPa})\right.$. $\left.\mathrm{pH}=7.38\right)$.

Simultaneous measures of $\mathrm{BP}$, tidal volume and flow are also recorded.

\section{Methods}

Animal model and physiological monitoring We studied 11 mongrel dogs weighing between 11.3 and $35.4 \mathrm{~kg}$. Anaesthesia was induced with intravenous pentobarbitone $30 \mathrm{mg} \cdot \mathrm{kg}^{-1}$ and was maintained with incremental $50 \mathrm{mg}$ doses as necessary. A low cervical tracheostomy was performed and a cuffed endotracheal tube was inserted through the small tracheal stoma into the intrathoracic trachea. Care was taken to prevent damage to the innervation or vascular supply of the trachea during tracheostomy. All animals were paralyzed with pancuronium $\left(0.2 \mathrm{mg} \cdot \mathrm{kg}^{-1}\right)$ and intermittant positive pressure ventilation (Bennett $\mathrm{MA}-1$ ) was used to maintain an arterial $\mathrm{PCO}_{2}\left(\mathrm{PaCO}_{2}\right)$ of approximately $5.33 \mathrm{kPa}(40 \mathrm{mmHg})$. Supplemental oxygen $\left(\mathrm{FIO}_{2}=0.40\right)$ was given to prevent hypoxaemia $\left(\mathrm{PaO}_{2}>100 \mathrm{mmHg}\right)$. A femoral arterial cannula was inserted to sample blood for blood gas analysis and to continuously record blood pressure (BP) on a Beckman dynograph recorder. Rectal temperature was also monitored.

The endotracheal tube was attached to a calibrated, heated pneumotachograph (Fleish \#2) which was connected to a differential transducer (Statham PM 5). The Fleisch pneumotachograph was calibrated with a linear accuracy to a flow rate of $20 \mathrm{~L} \cdot \mathrm{min}^{-1}$. This flow signal was integrated to obtain tidal volume, which was continuously recorded on the Beckman Dynograph (Fig. 1).

All animals were then ventilated with zero end-expiratory pressure. A tidal volume and flow rate was chosen to achieve a temperature-corrected $\mathrm{PaCO}_{2}$ of 5.0 to $6.4 \mathrm{kPa}(37.4-47.7 \mathrm{mmHg})$ which will be referred to as normocapnia.

A $9 \mathrm{~mm}$ polyvinylchloride SHILEY cuffed endotracheal tube, the cuff having been flushed with water to exclude air bubbles, was then inserted through the vocal cords into the pouch of the extrathoracic trachea above the tracheostomy. The cuff was then filled with water to a cuff pressure of 25-30 $\mathrm{mmHg}$ and connected via water-filled tubing, to a transducer (Bentley Trantec Model 800) placed at the same height as the dog's trachea. This system provided a continuous recording of the extrathoracic cuff pressure ${ }^{3}$ (PTE) in the tracheal segment above the tracheostomy stoma. Thus, the cuff measuring PTE was not exposed to airway pressure which was isolated to the lower airway by the cuff of the tracheostomy tube.

\section{PEEP at normocapnia}

While continuously monitoring BP, PTE, inspired and expired gas flow and volume, we suddenly applied $10 \mathrm{~cm} \mathrm{H}_{2} \mathrm{O}$ PEEP using the PEEP valve of the Bennett MA-1 ventilator. PEEP was maintained for a seven-minute measurement period during which arterial blood samples were analyzed for $\mathrm{PO}_{2}, \mathrm{PCO}_{2}$ and $\mathrm{pH}$ at the one minute and seven minute points. After sudden withdrawal of PEEP these parameters were monitored for 15-20 minutes prior to any further intervention.

\section{PEEP at hypocapnia}

To determine the tracheomotor response to PEEP at a lower $\mathrm{PaCO}_{2}$ we then increased minute volume $(\mathrm{VE})$. Tidal volume was kept constant while increasing respiratory frequency (f) from 9 to 19 breaths per minute. Arterial blood gases were assessed to assure a reduced $\mathrm{PaCO}_{2}$ ranging from 2.6 to $4.5 \mathrm{kPa}$ (19.4 to $34 \mathrm{mmHg}$ ). The result of increasing $f$ was a gradual reduction of PTE, reflecting loss of tracheomotor tone. 
Water had to be added to the cuffs of all dogs to maintain contact with the extrathoracic tracheal wall. We know that the PTE value when there is no contact with a surrounding structure at the cuff volume used is $6.6 \pm 2.3 \mathrm{mmHg}$. In five dogs water was added to the cuffs to create a PTE of $20.3 \pm 2.8$ $\mathrm{mmHg}$ (range 11.5-27.0) which was significantly lower than in the normocapneic phase of the experiment, but much greater than that measured when the cuffs were not in contact with surrounding structures. The total volume of water in these cuffs was $9.2 \pm 1.3 \mathrm{ml}$.

In the other six dogs more volume was added to the cuff $(14.9 \pm 1.4 \mathrm{ml})$ to retum PTE to a value similar to that in the normocapneic phase $(39.3 \pm$ $1.7 \mathrm{mmHg}$ ) (range $35.0-46.5 \mathrm{mmHg}$ ). Thus, for the hypocapneic phase of the study, we had two groups of animals which differed in the volume of water added to the cuffs, hence, the circumference of the isolated tracheal segment.

In each animal $10 \mathrm{~cm} \mathrm{H}_{2} \mathrm{O}$ PEEP was again applied to the airway and BP, PTE, flow and volume were monitored for a seven-minute period. Arterial blood samples were also taken at one and seven minutes and analyzed as above.

\section{PEEP with $\mathrm{CO}_{2}$ added}

At this point the water which had been added to the extrathoracic tracheal cuff was removed in all dogs. $\mathrm{CO}_{2}$ was then added to the inspired gas mixture to produce an inspired $\mathrm{CO}_{2}$ fraction of approximately four per cent. A further 15-20 minute stabilization period was allowed with zero end-expiratory pressure, and the rapid respiratory rate $(r=19)$. Arterial blood was sampled and analyzed to assure that normocapnia was present and PEEP was again applied to demonstrate that the PTE response of the experimental model could be returned to control levels by adding $\mathrm{CO}_{2}$. All measurements were again repeated over a seven-minute period.

\section{PEEP with hypocapnia and $\mathrm{HCl}$ infusion}

In six dogs the inspired $\mathrm{CO}_{2}$ was removed and hypocapnia returned ( $f=19$ ) without altering the respiratory frequency. After another 15-20 minute period, PEEP was again added to ensure a PTE response similar to that previously noted during the hypocapneic state. Having assured ourselves of the stability of the experimental model, an arterial blood sample was analyzed for $\mathrm{PO}_{2}, \mathrm{PCO}_{2}$ and $\mathrm{pH}$,

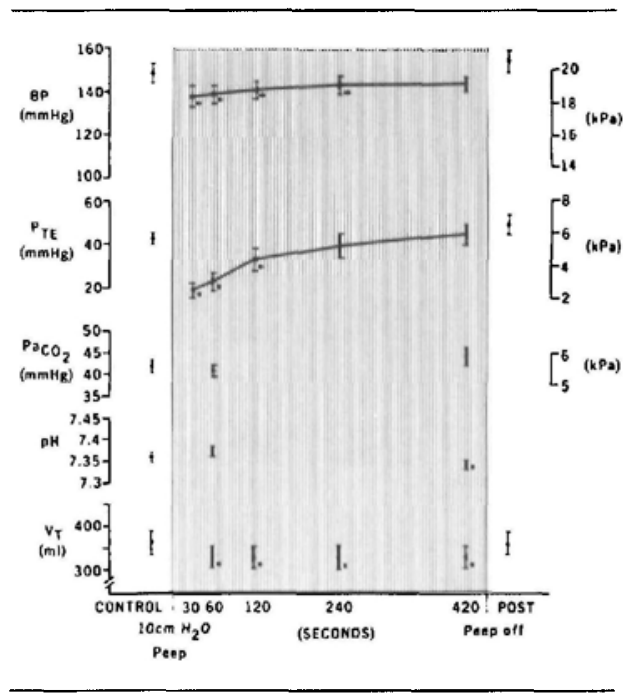

FIGURE 2 Mean values ( \pm SEM) of the measured variables after sudden application of $10 \mathrm{~cm} \mathrm{H}_{2} \mathrm{O}$ PEEP at normocapnia and $\mathrm{f}=9 .(\mathrm{n}=11)$.

after which we began an infusion of a $0.1 \mathrm{~N}$ hydrochloric acid solution $(\mathrm{HCl})$ at a steady rate. Arterial blood was sampled and analyzed at fiveminute intervals until a mean $\mathrm{pH}$ of 7.26 was achieved, while maintaining hypocapnia $\left(\mathrm{PaCO}_{2}=\right.$ $3.5 \pm 0.3 \mathrm{kPa}(26.6 \pm 2.2 \mathrm{mmHg})$. When acidemia and hypocapnia were present $10 \mathrm{~cm} \mathrm{H}_{2} \mathrm{O}$ PEEP was again applied for a seven-minute interval and all measurements repeated.

\section{Statistical techniques}

Statistical analysis was performed using Student's paired t-test and two way analysis of variance followed by Dunnett's multiple range test for sequential data. All results are reported as mean \pm SEM, and $p<0.05$ is considered significant.

\section{Results}

PEEP at normocapnia

Figure 1 demonstrates a typical response of PTE to the sudden application of $10 \mathrm{~cm} \mathrm{H} \mathrm{H}_{2} \mathrm{O}$ PEEP with $\mathrm{PaCO}_{2}=38 \mathrm{mmHg}(5.1 \mathrm{kPa})$ and $\mathrm{pH}$ of 7.38 . Figure 2 shows mean \pm SEM of $B P$, PTE, tidal volume, $\mathrm{PaCO}_{2}$ and $\mathrm{pH}$ after the application of PEEP during normocapnia. A significant decrease of PTE is noted at 30,60 and 120 seconds after 


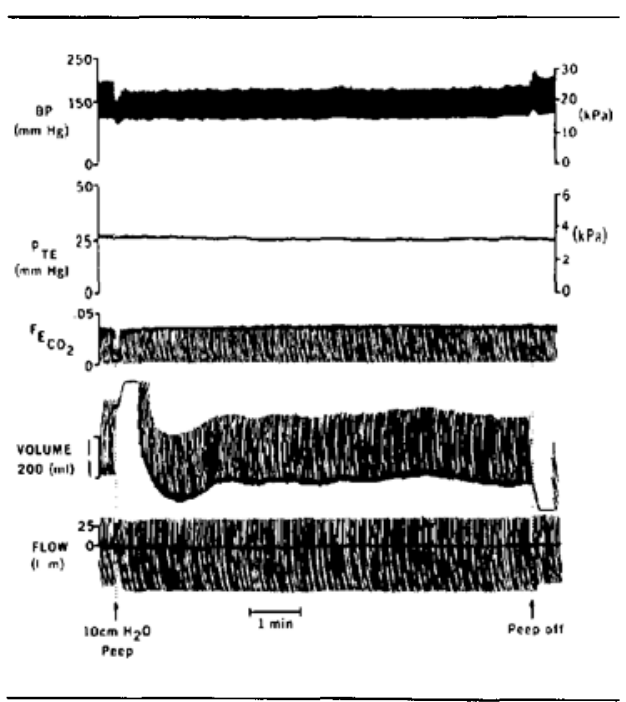

FIGURE 3 Simultaneous traces are shown during PEEP application with the animal hyperventilated ( $\mathrm{f}=19, \mathrm{PaCO}_{2}=$ $31 \mathrm{mmHg}(4.1 \mathrm{kPa}), \mathrm{pH}=7.47)$

initiation of PEEP, that was associated with a decrease of $\mathrm{BP}$, but no change in $\mathrm{PaCO}_{2}$ or $\mathrm{pH}$.

In every dog when PEEP was applied to the airway the pneumotachograph flow signal was altered by sudden pressurization of the airway (Fig. 1). With this change in velocity profile small reductions in tidal volume were measured after PEEP application. This change in volume occurred equally in all groups (Figures 2, 4a, 4b and 5) and thus was not related to the differences noted between groups.

\section{PEEP at hypocapnia}

Figure 3 demonstrates a typical response to PEEP in one dog after the respiratory frequency had been increased to 19 breaths $/ \mathrm{min}$ with $\mathrm{PaCO}_{2}=31$ $\mathrm{mmHg}(4.1 \mathrm{kPa})$ and $\mathrm{pH}=7.47$. No detectable change in PTE was observed. In this dog PTE had not been returned to a similar value to that present in the normocapneic state (Fig. 1).

Figure 4a shows mean \pm SEM for BP, PTE, $\mathrm{PaCO}_{2} \mathrm{pH}$ and $\mathrm{VT}_{\mathrm{T}}$ before and during a sevenminute application of $10 \mathrm{~cm} \mathrm{H}_{2} \mathrm{O}$ PEEP to the lower airway in five dogs. In these dogs PTE was significantly lower than in the normocapneic state (Fig. 2) as sufficient water had not been added to the cuff to return PTE to this level. However, PTE is much higher than the measured cuff pressure when there is no contact with surrounding structures $<5$ $\mathrm{mmHg}$ ) at the same cuff volume. PTE is significantly lower reflecting the dilation of the airway resulting from increasing respiratory frequency from 9 to 19 breaths/min and reducing $\mathrm{PaCO}_{2}$ from $44.1 \pm 3.2 \mathrm{mmHg}$ to $30.4 \pm 1.2 \mathrm{mmHg}$. Although a similar change in BP was observed compared to normocapnia (Fig. 2), no change in PTE was detected.

In 6 dogs (Fig. 4b), PTE was returned to a value (PTE $=39.3 \pm 1.7 \mathrm{mmHg}$ ) approximately equal to that present in the normocapneic state (Fig. 2) by adding water to the cuff prior to applying PEEP. When $10 \mathrm{~cm} \mathrm{H}_{2} \mathrm{O}$ PEEP was applied to the lower airway, a similar decrease in BP was observed compared to the normocapneic dogs (Fig. 2); however, no change in PTE was detected. A small increase in $\mathrm{PaCO}_{2}$ and decrease of $\mathrm{pH}$ accompanied PEEP in this group.

PEEP with $\mathrm{CO}_{2}$ added

After withdrawing PEEP, and allowing a 15-20 minute stabilization period ( $f=19 / \mathrm{min}$ ), we added $\mathrm{CO}_{2}$ to the inspired gas mixture such that dogs were inspiring approximately 4 per cent $\mathrm{CO}_{2}$. This mixture was adjusted to obtain a measured $\mathrm{PaCO}_{2}$ of $47.03 \pm 3.2 \mathrm{mmHg}$. Water which had been added to the cuffs during the hypocapneic phase of the experiment had to be removed prior to applying PEEP to maintain PTE close to that used in the normocapneic experiment (Fig. 2). Figure 5 shows that PEEP caused a significant decrease in BP, with a small but significant decrease in PTE occurring at 30 seconds, returning to control value for the duration of the seven-minute measurement. This tracheal dilation 30 seconds after PEEP was not associated with a change in $\mathrm{PaCO}_{2}$ or $\mathrm{pH}$. An increase in $\mathrm{PaCO}_{2}$ at 420 seconds with a decrease in pH was not associated with altered PTE and could have resulted from increased deadspace and reduced cardiac output with PEEP.

\section{PEEP with hypocapnia and $\mathrm{HCl}$ infusion}

After discontinuation of the inspired $\mathrm{CO}_{2}$, six animals were hyperventilated ( $f=19 / \mathrm{min}$ ), and a tendency towards mild metabolic acidemia was found $\left(\mathrm{pH}=7.47 \pm 0.02 ; \mathrm{PaCO}_{2}=27.5 \pm 2.4\right.$ $\mathrm{mmHg}$ ). At this point, $0.1 \mathrm{~N} \mathrm{HCl}$ infusion was started. A gradual significant $(p<0.005)$ increase 


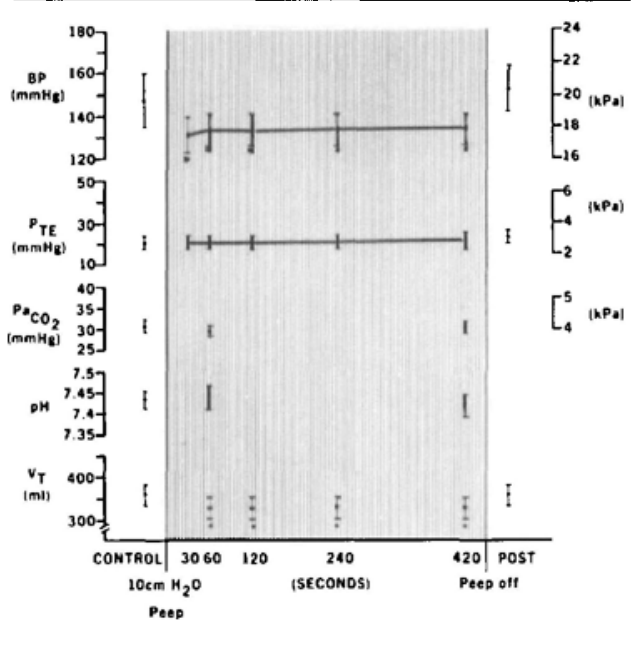

FIGURE 4(a) Mean ( \pm SEM) of the measured variables during sudden application of PEEP with hypocapnia in 5 dogs with low values of PTE.

in PTE from $28.2 \pm 2.9 \mathrm{mmHg}(3.8 \pm 0.4 \mathrm{kPa})$ to $42.7 \pm 1.3 \mathrm{mmHg}(5.7 \pm 0.2 \mathrm{kPa})$ was noted over 30-70 minutes as $\mathrm{pH}$ decreased with no change in $\mathrm{PaCO}_{2}$ (Table). With the application of PEEP a significant $(p<0.05)$ decrease in PTE occurred at the 30-second measurement (Table).

\section{Discussion}

Isolating a cervical tracheal segment from lower airway pressure, by performing a low cervical tracheostomy, enabled us to assess the effect of PEEP applied to the lower airway on tracheomotor tone independent of local pressure effects of PEEP on the trachea.

This study demonstrates that, in a segment of trachea isolated from airway pressure effects, airway dilation occurred in response to the sudden application of $10 \mathrm{~cm} \mathrm{H}_{2} \mathrm{O}$ PEEP. It is important to emphasize that the experimental model was an anaesthetized mongrel $\operatorname{dog}^{4}$ and pentobarbitone has been shown to reduce reflex tracheomotor responses to stimuli in such a model.

The relationship of this model to humans with irritable airway disease or acute asthma remains speculative. Parham et al. ${ }^{5}$ suggested that the transient reversal of methacholine-induced airway constriction by lung inflation in normal human

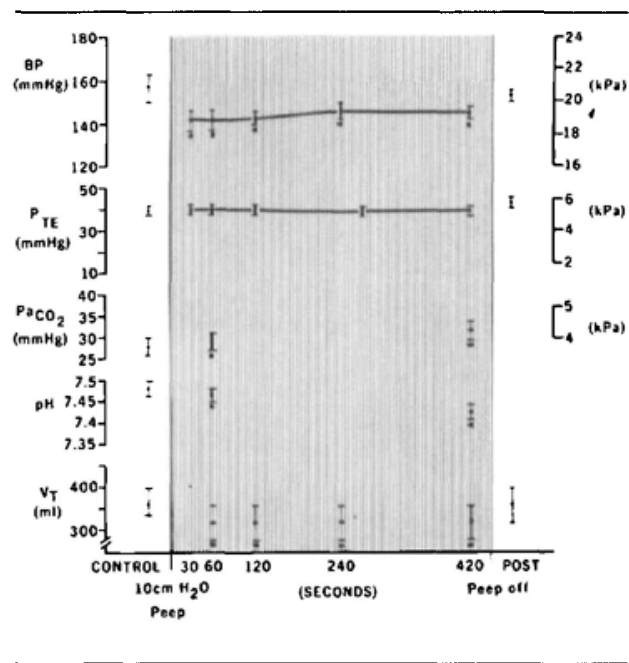

FIGURE 4(b) Mean ( \pm SEM) of measured variables during sudden application of PEEP with hypocapnia in six animals with high values of PTE created by adding water to the cuffs.

subjects is reduced in patients with airway hyperreactivity. Therefore findings in normal subjects (dogs or humans) may not be found in patients with asthma or hyper-responsive airways.

In spite of these limitations this study does suggest that PEEP causes an immediate but transient (less than four minutes) reduction in normal tracheal smooth muscle tone (Fig. 2) at normocapnia and $\mathrm{pH}=7.36 \pm 0.01$.

Whether this change in tracheomotor tone is reflected by altered smooth muscle tone of the lower airway is unknown. The extrathoracic tracheal cuff technique has been shown $\mathrm{n}^{3}$ to detect very small changes in the circumference of adjacent intrathoracic tracheal segments. As well, a sustained increase in lung volume caused by a maximal inflation manoeuvre has been shown to decrease airway resistance. ${ }^{6}$ Therefore, there is considerable physiologic evidence to suggest that sudden increases in lung volume reduce airway smooth muscle tone in resistance airways. Our study suggests that the reduction in airway smooth muscle tone caused by a sudden sustained application of 10 $\mathrm{cm} \mathrm{H}_{2} \mathrm{O}$ PEEP is transient. Whether this response would be beneficial to an asthmatic patient with hyperinflated lungs and airway closure remains to be determined. 
TABLE Results - hypocapnia and $\mathrm{HCl}$ infusion

\begin{tabular}{|c|c|c|c|c|c|}
\hline & $p H$ & $\mathrm{PaCO}_{2}$ & $\mathrm{PaO}_{2}$ & $\overline{B P}$ & $P \overline{T E}$ \\
\hline Pre- $\mathrm{HCl}$ & $7.47=0.02$ & $\begin{array}{l}27.5 \pm 2.4 \\
(3.7 \pm 0.3)\end{array}$ & $\begin{array}{l}112.7 \pm 2 \\
(15.2 \pm 0.3)\end{array}$ & $\begin{array}{c}156 \pm 5.8 \\
(20.8 \pm 0.8)\end{array}$ & $\begin{array}{l}28.2 \pm 2.9 \\
(3.8 \pm 0.4)\end{array}$ \\
\hline \multicolumn{6}{|c|}{$\mathrm{HCl}$ infusion $\longrightarrow$} \\
\hline Control & $7.26 \pm 0.02 \dagger$ & $\begin{array}{l}26.6 \pm 2.2 \\
(3.5 \pm 0.3)\end{array}$ & $\begin{array}{c}123 \pm 4.6 \\
(16.4 \pm 0.6)\end{array}$ & $\begin{array}{l}142 \pm 7.6 \\
(19 \pm 1.0)\end{array}$ & $\begin{aligned} 42.7 & \pm 1.3 \dagger \\
(5.7 & \pm 0.2) \dagger\end{aligned}$ \\
\hline \multicolumn{6}{|l|}{ PEEP $\longrightarrow$} \\
\hline 30 seconds & & & & $\begin{array}{l}124.8 \pm 14.2 \\
(16.6 \pm 1.9)\end{array}$ & $\begin{array}{l}33.8 \pm 2.4^{*} \\
(4.5 \pm 0.3)^{*}\end{array}$ \\
\hline 1 minute & $7.22 \pm 0.04$ & $\begin{array}{l}27.2 \pm 2.4 \\
(3.6 \pm 0.3)\end{array}$ & $\begin{array}{l}117.8 \pm 2.1 \\
(15.7 \pm 0.3)\end{array}$ & $\begin{array}{l}132.7 \pm 10.8 \\
(17.7 \pm 1.4)\end{array}$ & $\begin{array}{l}36.2 \pm 3.8 \\
(4.8 \pm 0.5)\end{array}$ \\
\hline 2 minutes & & & & $\begin{array}{l}131.8 \pm 9.6 \\
(17.6 \pm 1.3)\end{array}$ & $\begin{array}{l}4 ! .0 \pm 3.8 \\
(5.5 \pm 0.5)\end{array}$ \\
\hline 4 minutes & & & & $\begin{array}{l}131.3 \pm 8.3 \\
(17.5 \pm 1.1)\end{array}$ & $\begin{array}{l}43.8 \pm 3.8 \\
(5.8 \pm 0.5)\end{array}$ \\
\hline 7 minutes & $7.18 \pm 0.5$ & $\begin{array}{l}27.2 \pm 2.3 \\
(3.6 \pm 0.3)\end{array}$ & $\begin{aligned} 114 & =3.4 \\
(15.2 & \pm 0.5)\end{aligned}$ & $\begin{array}{l}124.3 \pm 10.8 \\
(16.6 \pm 1.4)\end{array}$ & $\begin{array}{l}44.7 \pm 4.0 \\
(6.0 \pm 0.5)\end{array}$ \\
\hline
\end{tabular}

Legend: Mean ( \pm SEM) values before and during $0.1 \mathrm{~N} \mathrm{HCl}$ infusion in six dogs, showing the observed changes after PEEP. Values reported as mmHg with $\mathrm{kPa}$ in parentheses.

${ }^{*} \mathrm{p}<0.05, \dagger_{\mathrm{p}}<0.005$.

The mechanism of this transient relaxation of tracheomotor tone was not investigated in our study. PEEP increases sympathetic nervous system activity ${ }^{7}$ and a catechol-mediated airway dilation, perhaps secondary to haemodynamic changes is one possible explanation. Nadel et al. ${ }^{\prime}$ showed that tracheal dilation in response to lung inflation could be abolished by vagotomy. Thus the relaxation of tracheomotor tone in our study could also be secondary to a vagal reflex resulting from the increase in lung volume which occurs with PEEP. ${ }^{8}$ Changes in tracheomotor tone mediated by such cholinergic stimuli have been shown to occur in large as well as small resistance airways. ${ }^{9}$

Orehek $^{10}$ has reviewed the complex interaction of neural and humoral factors that control airway responses to changes in $\mathrm{PCO}_{2}$. In dogs, bronchoconstriction is observed during arterial hypercapnia even while $\mathrm{PCO}_{2}$ in the airways remains constant. ${ }^{11}$ In some canine models of bronchoconstriction, hypercapnia can relax airways; while in others it is ineffective. In the studies reviewed by Orehek, ${ }^{10}$ the bronchomotor effect of $\mathrm{CO}_{2}$ appeared to be mediated by cholinergic nerves. In our study the acute changes in PTE were not related to acute alterations in end-tidal $\mathrm{CO}_{2}$ levels (Fig. 1 and 3) although the validity of comparing end-tidal samples at different respiratory rates is acknowledged.

Hypocapneic alkalemia ( $\mathrm{pH} 7.46 \pm 0.02)$ caused by increasing respiratory frequency ( $f=19 / \mathrm{min}$ ) dilated the trachea and abolished the tracheomotor response to PEEP. Further tracheal dilation in response to PEEP was absent when small volumes of water were added to the cuff (Fig. 4a) as well as high volumes (Fig. 4b). This suggests that the hypocapneic dilation caused by increasing $f$ could not be further reduced. These data suggest that, at the degree of tracheomotor tone present in hypocapneic mongrel dogs, PEEP does not cause a detectable decrease in tone. This is consistent with animal data ${ }^{1}$ derived from studies on the tracheomotor response to a single lung inflation which was diminished if the lung was already partially inflated. If tracheal tone, however, is returned towards normal by adding $\mathrm{CO}_{2}$ to inspired gas, hence increasing both alveolar and arterial $\mathrm{PCO}_{2}$ levels (Fig. 5), or by exogenous acidification (Table) then tracheal dilation in response to PEEP occurs. The PEEP effect on tracheomotor tone depends on the resting level of airway smooth muscle tone. 


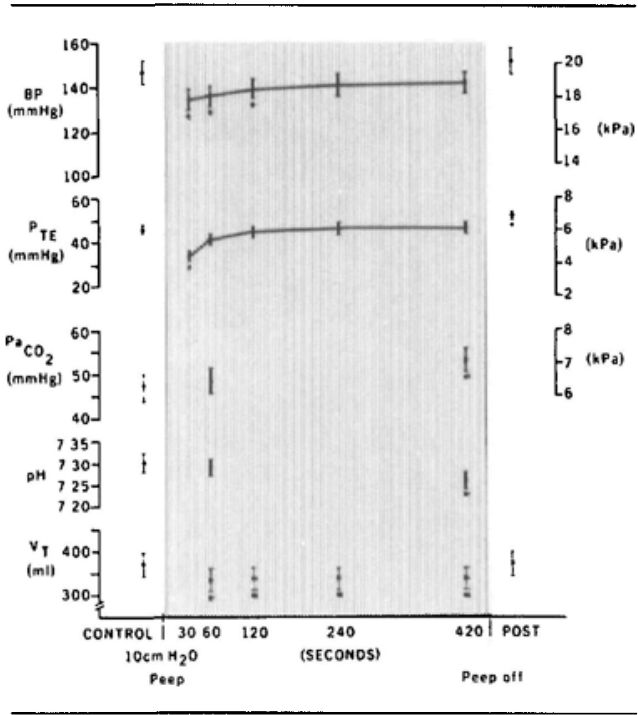

FIGURE 5 Mean ( \pm SEM) of measured variables during sudden application of PEEP in hyperventilated ( $f=19 / \mathrm{min}$ ) dogs with $\mathrm{CO}_{2}$ added to the inspired gas mixture ( $n=6$ ).

Severinghaus et al. ${ }^{12}$ suggested that local mechanisms control airway smooth muscle tone, and hence ventilation: perfusion matching. Our data suggest that systemic acid-base balance also contributes to the magnitude of the tracheomotor response to PEEP. The increase of PTE (Table) and the partial return of the PTE response to $\mathrm{PEEP}$ during the $\mathrm{HCl}$ infusion suggests that acidemia, which is often present in critically ill asthmatic subjects, may contribute to the increased airway smooth muscle tone. Since the animal model used in our study was most unstable during the $\mathrm{HCl}$ infusion, we cannot reliably compare the magnitude of PEEP response after $\mathrm{HCl}$ infusion with those prior to this phase of the study, when the model was more stable.

Quantitative PTE changes after pharmacologic stimuli in any single animal appear to bear a near-linear relationship to simultaneous changes in intrathoracic tracheal circumference. ${ }^{3}$ However, we have been unable to predict changes in tracheal circumference ${ }^{3}$ or more conventional airway resistance measurements (unpublished data) from PTE changes between animals. Whether the magnitude of airway dilation demonstrated in this study reflects clinically important alterations in airway tone or resistance with detectable reductions in gas trapping remains unknown. What is certain from our study is that transient tracheal dilation occurs independent of the airway pressure effects of PEEP, which could also mechanically distend airways due to the increased transpulmonary pressure.

The effect of PEEP on respiratory function is a complex interaction of respiratory and cardiovascular changes. Attention has focused on the beneficial effects of PEEP on the reduced functional residual capacity that accompanies respiratory failure in a number of disease states. Qvist et al ${ }^{2}$ have suggested that high level PEEP might also benefit selected patients with air-trapping and severe asthma. This therapy is not without detrimental consequences; ${ }^{13}$ however it is possible that the beneficial results ${ }^{2}$ in extreme hypercapneic and acidemic cases could be due to a transient reduction of smooth muscle tone accompanied by the mechanical advantage of increasing expiratory airway patency with PEEP. Our study suggests that any reduction of large airway tone by the application of PEEP is transient ( $<4$ minutes) and would be attenuated by hypocapnia associated with hyperventilation.

Further study is warranted to elucidate the extent of smooth muscle relaxation on smaller airways in response to $P E E P$ and the relative importance of this relaxation in various clinical states.

\section{Acknowledgement}

The author wishes to thank Colin Kay, Elly Hobbs and Julia Ycas for their technical assistance, and Pat Slusarenko for preparing the manuscript. Funding for this study was provided by the Ontario Heart Foundation.

\section{References}

1 Widdicombe JG, Nadel JA. Reflex effects of lung inflation on tracheal volume. J Appl Physiol 1963; 18: 681-6.

2 Qvist J, Anderson JB, Pemberton M, Bennike K. High level PEEP in severe asthma. $N$ Engl J Med 1982; 307: 1347-8

3 Byrick RJ, Hobbs EG, Kay JC. Extrathoracic cuff pressure reflects changes of intrathoracic large airway circumference. Anesth Analg 1982; 61: 693-8.

4 Holtzman MJ, Hahn HL, Sasaki K, et al. Selective effect of general anesthetics on reflex bronchoconstrictor responses in dogs. J Appl Physiol 1982; 53: $126-33$. 
5 Parham WM, Shepard RH, Norman PS, Fish JE. Analysis of time course and magnitude of lung inflation effects on airway tone: relation to airway reactivity. Am Rev Respir Dis 1983; 128: 240-5.

6 Nadel $J A$, Tierney $D F$. Effect of a previous deep inspiration on airway resistance in man. J Appl Physiol 1961; 16: 717-19.

7 Chernow B, Saldono S, Cook D, et al. Positive endexpiratory pressure increases sympathetic nervous system activity. Crit Care Med 1983; 11: 233.

8 Abboud N, Rehder $K$, Rodarte JR, et al. Lung volumes and closing capacity with continuous positive airway pressure. Anesthesiology 1975; 42: 138.

9 Woolcock AJ, Macklem PT, Hogg JC, et al. Effect of vagal stimulation on central and peripheral airways in dogs. J Appl Physiol 1969; 26: 806-13.

10 Orehek J. International Review of Physiology. Respiratory Physiology III, Vol. 23. Edited by John G. Widdicombe, University Park Press, Baltimore, 1981, pg 31-3.

11 Ingram $R H J r$. Effects of airway versus arterial $\mathrm{CO}_{2}$ changes on lung mechanies in dogs. J Appl Physiol 1975; 38: 603-7.

12 Severinghaus $J W$, Swenson EW, Finley TN, Lategala MT, Williams $J$. Unilateral hypoventilation produced in dogs by occluding one pulmonary artery. J Appl Physiol 1961; 16: 53-60.

13 Nolop KB, Graham BS, Bernard G. High-level PEEP in severe asthma. N Eng! J Med 1983; 308: 725-6.

\section{Résumé}

L'influence de la pression positive de fin d'expiration (PEEP) sur le tonus des muscles lisses des voies aériennes est difficile à apprécier par les techniques usuelles de mesure des résistances et compliance pulmonaires. Dans cette étude, grâce à une trachéotomie cervicale basse, nous avons pu isoler la partie extrathoracique de la trachée des pressions des voies aériennes basses. Un ballonnet de tube endotrachéal, préalablement rempli d'eau, était placé dans le segment isolé de la trachèe extrathoracique. La pression enregistrée dans ce ballonnet était considérée comme une mesure du tonus de la motricité trachéale (Pte).

L'application subite d'une PEEP de $10 \mathrm{CmH}_{2} \mathrm{O}$ chez des animaux normocapniques a entrainé une dilatation immédiate dans ce segment trachéal extrathoracique (Pte réduite de $5.7 \pm 0.3 \mathrm{kPa}$ à $2.4 \pm 0.4 \mathrm{kPa}$ ). Cette réduction du tonus trachéomoteur était fugace et retournail au niveau de contrôle en moins de quatre minutes en dépit du maintien de la PEEP dans les voies aériennes basses.

Dans un autre temps, la fréquence respiratoire étaif augmentée à 19 par minute, la $P_{C O}$ réduite à $3.9 \pm 0.2$ $k P a$ au cours d'une ventilation sans PEEP. Dans ces conditions, l'application de $10 \mathrm{CmH}_{2} \mathrm{O}$ de PEEP aux voies aériennes basses ne provoque aucune dilatation trachéale. Si on ajoutait du $\mathrm{CO}_{2}$ au cours de cette hyperventilation de 19 par minute, la $\mathrm{PaCO}_{2}$ augmentail de $4.2 \pm 0.2 \mathrm{kPa}$ à $6.7 \pm 0.4 \mathrm{kPa}$ et on voyait réapparaître une dilatation trachéale en réponse de l'application de la PEEP.

Finalement une infusion de $H C L$ à $0.1 \mathrm{~N}$ a été administrée à des animaux hypocapniques $\left(\mathrm{PaCO}_{2} 3.7 \pm\right.$ $0.3 \mathrm{kPa}$ et $\mathrm{pH}=7.47 \pm 0.02$ ). Cette infusion, après $30 \mathrm{a}$ 70 minutes, a diminué le pH à $7.26 \pm 0.02$ et la $\mathrm{PaCO}_{2}$ est demeurée à $3.5 \pm 0.3 \mathrm{kPa}$. Dans ces conditions l'application d'une PEEP $10 \mathrm{cmH}_{2} \mathrm{O}$ a provoqué une trachéodilatation détectable mais de moindre intensité.

Nous en concluons que:

1. L'application soudaine d'une PEEP à $10 \mathrm{cmH}_{2} \mathrm{O}$ provoque une réduction transitoire du tonus trachéonoteur $(<4$ minutes $)$.

2. Cette réduction du tonus trachéomoteur est partiellement éliminée par l'hyperventilation avec hypocapnie.

3. Cette diminution de la réponse du muscle trachéal d la PEEP parl'hyperventilation est partiellement corrigée par l'addition de $\mathrm{CO}_{2}$ aux gaz inspirés ou l'acidification systémique par le HCL.

Ces résultats suggèrent que la dilatation trachéale résuitant de l'augmentation du volume pulmonaire par la PEEP est fugace et variable; elle dépend de facteurs tels que l'équilibre acido-basique systémique, les $\mathrm{PCO}_{2}$ alvéolaire et artérielle et les volumes pulmonaires. Ces facteurs ont autant d'influence sur le tonus moteur des voies aériennes que les infiux sympathiques et parasympathiques du système nerveux autonome. 